\title{
Medical developments get small investors' backing in Canada
}

Ottawa. In an unusual financial experiment designed to ensure that Canadian discoveries are exploited at home rather than abroad, medical scientists have set up a venture-capital fund. In under 18 months the fund has attracted almost $C \$ 190$ million (US $\$ 140$ million) from 47,000 individuals, each investing an average of $C \$ 4,000$.

The Canadian Medical Discoveries Fund (CMDF) arose from an initiative of the Medical Research Council (MRC) of Canada. Its partners are MDS Health Ventures Capital Corporation, Talvest Fund Management and the Professional Institute of the Public Service of Canada.

Calvin R. Stiller, a physician from London, Ontario, and chairman of the fund, says he expects investment in what is already one of the top ten venture-capital funds in North America to reach $C \$ 500$ million in three years.

The fund resulted from a study commissioned by the MRC to find out why, although the quality of science in Canada compares well with that in other developed countries, few Canadian discoveries are successfully commercialized within its borders. The study concluded that the reason was a lack of venture and pre-venture capital.

The fund takes advantage of Canadian legislation that provides small individual investors with significant tax incentives to invest in venture-capital funds, provided they do not withdraw their money within specific terms, typically five to eight years.

The CMDF was created under this legislation with the aim of funding the commercialization of pre-discovery, discovery and post-discovery medical research. The MRC acts as a strategic partner, helping to identify projects for funding and monitoring their progress.

Nine projects have so far been funded, most of which have or had some connection with the MRC. They include investments in companies researching apoptosis, novel therapeutics to inhibit cancer spread and to destroy malignant tumours, 3D ultrasoundimaging systems, anti-infective compounds aimed at drug-resistant bacteria, an automated system for analysis of pap smear tests, three compounds for osteoporosis treatment, and vaccines against infectious diseases and cancers. Individual grants range from $C \$ 1$ million to $C \$ 13.5$ million.

CMDF provided much of the stimulus for the doubling of venture capital that occurred in the year 1994-95 alone.

Two months ago the fund created University Medical Discoveries Inc., which will provide universities with money and expertise to patent discoveries quickly at no cost to themselves.

David Spurgeon

\section{Liability clause blocks talks on biosafety protocol}

London. Developing countries ended a week of negotiations in Aarhus, Denmark, last Friday, divided over the content of proposed internationally binding regulations governing the use of genetically modified organisms (GMOs).

Member countries of the G77 group last year agreed to proposals for a new international biosafety law (or protocol) regulating the import and export of GMOs, referred to as 'transboundary movement' (see Nature 378, 326; 1995).

Last week's meetings were intended to start negotiations on the protocol's content. But a breakaway faction, including Malaysia, Ethiopia and Mauritius, tried to widen the scope of transboundary movement to cover handling and use of GMOs.

This group is also lobbying for a clause that provides compensation where GMO release damages human health and the environment. They want a related clause that assesses - and possibly compensates for - the impact of biotechnology on traditional agriculture.

"The question of liability and socioeconomic impact of GMOs is a matter of grave concern to less developed countries," says A. H. Zakri, head of Malaysia's delegation to the United Nations (UN) biodiversity convention, and deputy vice-chancellor of the Universiti Kebangasaan Malaysia, near Kuala Lumpur. "I know that this is not biosafety per se, but, since GMOs present a potential risk to our environments and economies, we would like this to be included in the protocol."

But the demands are being resisted by the European Union (EU), industry representatives such as the BioIndustry Association, the lobby group for British biotechnology companies, and some developing countries. They feel that stronger regulations will inhibit emerging and established biotechnology industries. They could also limit the attractiveness of developing countries to multinationals that may want to invest in bio-prospecting or GMO field trials.

Malpede Diego, head of the Argentine delegation and a member of Argentina's mission to the UN in Geneva, says: "We think it is premature to discuss liability in GMO release. We understand the concerns relating to socio-economic consequences [of the use of GMOs]. But this is a large and complex issue. It is hard to see why this should be included in a biosafety protocol."

The European Union has taken a similar line. A statement issued to coincide with the Aarhus meeting said that adverse environmental effects from the transboundary movement of GMOs were "unlikely", on account of their "contained

\section{IMAGE \\ UNAVAILABLE \\ FOR COPYRIGHT REASONS}

Seed change: $\mathbf{G 7 7}$ countries are concerned over impact of biotechnology on agriculture.

use and separation from the environment".

The Denmark meeting brought together the ad hoc group of experts on biosafety convened by the 150 -member UN biodiversity convention to write a draft protocol. All the delegates agreed that any exporter would need to obtain the prior informed agreement of the country to which GMOs are to be sent. The exporting organization would need to comply with local safety regulations.

But there was further disagreement on the definitions of terms to be used in a protocol, including the phrases "living modified organism' (LMO), which is now used in all official documentation, and 'transboundary movement' of LMOs.

The EU says LMO refers to "any biological entity capable of replication or of transferring genetic material in which the genetic material has been altered in a way that does not occur naturally by mating and/or natural recombination". But the breakaway G77 countries say that LMO must also cover any product that arises from a process involving genetic modification. Until this issue is resolved, the experts' group will not be able to begin classifying which LMOs pose a health or environmental hazard.

The EU also suggests that the protocol could be restricted to "unintended" movement of modified organisms between states. Some aspects of authorized movement of LMOs, according to the EU statement, may already be covered by UN rules on the transport of dangerous goods.

A draft text of the protocol is expected to be completed by 1998 . One hundred and fifty-two countries and the EU have signed and ratified the convention, which was opened for signature at the Earth Summit in Rio de Janeiro in 1992. The United States has not yet ratified it. 